\title{
Isolated trigonocephaly
}

INSERM

\section{Source}

INSERM. (1999). Orphanet: an online rare disease and orphan drug data base. Isolated trigonocephaly. ORPHA:3366

Isolated trigonocephaly is a nonsyndromic form of craniosynostosis characterized by the premature fusion of the metopic suture. 